\title{
Assessment of Awareness, Attitude and Desire for Labor Analgesia and Associated Factors Among Pregnant Women in Ethiopia: A Cross-Sectional Study
}

\author{
Misganaw Mengie Workie · Wubie Birlie Chekol • Demeke Yilkal Fentie • \\ Seid Adem Ahmed • Yosef Belay Bizuneh
}

Received: August 3, 2020 / Accepted: October 14, 2020 / Published online: October 27, 2020

(C) The Author(s) 2020

\begin{abstract}
Introduction: Labor pain is the worst imaginable pain that women experience during their childbearing years. Untreated labor pain has numerous negative consequences, for both the mother and her fetus. Low levels of awareness and attitudes among pregnant women about labor analgesia is a major challenge that affects outcomes for both the mother and fetus. Therefore, this study aimed to assess the awareness of, attitude towards and desire for labor analgesia and its associated factors among pregnant women who visited an antenatal care facility.

Methods: An institution-based, cross-sectional study was conducted from February to March 2019. Data were collected using semi-structured questionnaires by a convenience sampling technique. Data were entered using EpiData 4.2 and exported to SPSS version 20 software for analysis. Both bivariate and multivariate binary
\end{abstract}

Electronic supplementary material The online version of this article (https://doi.org/10.1007/s40122020-00212-1) contains supplementary material, which is available to authorized users.

M. M. Workie · W. B. Chekol (ه) - D. Y. Fentie · S. A. Ahmed . Y. B. Bizuneh

Department of Anesthesia, College of Medicine and

Health Sciences, University of Gondar, Gondar,

Ethiopia

e-mail: birliewubie@gmail.com logistic regression analysis were used to identify factors associated with awareness, attitude and desire for labor analgesia among pregnant women. Crude odds ratio (COR) and adjusted odds ratio (AOR) were calculated to show the strength of association.

Results: A total of 410 participants were included. Thirty-three (8\%) of the pregnant women who visited the antenatal care facility were found to have an awareness of labor analgesia. In multivariate analysis, the likelihood of having awareness of labor analgesia was 7.227 times (AOR: 7.227, 95\%, CI 2.406-21.720) greater among parous versus nulliparous mothers. The odds of having awareness of labor analgesia were 3.133 times (AOR: 3.133, 95\%; CI 1.144-8.581) greater among government employees than among housewives. The odds of having a good attitude towards labor analgesia were 6.488 times (AOR: $6.488,95 \% \mathrm{CI}$ 1.894-22.227) higher in government employees than in farmers. Women in the age group of 25-31 years were 1.815 times more likely to want labor analgesia for their next delivery (AOR: 1.815, 95\% CI 1.103-2.989).

Conclusions: The awareness of labor analgesia among pregnant women was low. There is a need for teamwork by all stakeholders in health sectors to improve attitudes and increase the desire for labor analgesia among pregnant women who visit antenatal care facilities. 
Keywords: Attitude; Awareness; Desire; Labor analgesia; Pregnant women

\section{Key Summary Points}

Why carry out this study?

In the University of Gondar

Comprehensive Specialized Hospital there are many experts who can treat labor pain, even with an epidural, but the percentage of parturients requesting labor analgesia is low.

In Ethiopia, there have been no studies on this subject, so the baseline data in this study could open the door to further research activity.

\section{What was learned from the study?}

The awareness of labor analgesia among pregnant women was low.

There is need for teamwork by all stakeholders in health sectors to improve attitudes and increase the desire for labor analgesia among pregnant women who visit an antenatal care facility.

\section{DIGITAL FEATURES}

This article is published with digital features, including a summary slide, to facilitate understanding of the article. To view digital features for this article go to https://doi.org/10.6084/ m9.figshare.13084601.

\section{INTRODUCTION}

Labor pain is among the worst imaginable pain that women can experience during their childbearing years $[1,2]$. Labor pain is due to frequent uterine contraction and cervical dilatation, transmitted through the sympathetic chain of T10-S1 and perineal stretching through S2-S4 [3].
Untreated labor pain leads to maternal hypertension, hyperventilation and excessive release of catecholamine, which results in diminishing oxygen transfer to the fetus. Severe pain, anxiety and increased catecholamine levels are associated with prolonged or dysfunctional labor. Many of these effects are mitigated by effective pain relief methods that may benefit the mother and fetus [4, 5]. Women in developing countries experience postnatal depression at rates that are comparable to or higher than those in developed countries $[6,7]$.

The American College of Obstetricians and Gynecologists and the American Society of Anesthesiologists agree that there are no other circumstances under which it is acceptable for a person to experience untreated severe pain. It is amenable to intervention while under a physician's care [8].

Pain management during labor has undergone various developments since 1847, when Simpson found that chloroform could help in relieving the pain that women felt during labor. Nowadays, there are different types of pain relief methods in labor pain management, both non-pharmacological and pharmacological. The ideal pain alleviation method must be safe, effective, timely, efficient, equitable and woman-centered, and ideally should not interfere with labor or the mobility of women in labor $[1,2,9]$. It has been speculated that labor analgesia, especially epidural, prolongs the stages of labor and increases the rate of cesarean section, but studies have shown that analgesia has no effect in prolonging labor; in fact, it decreases the cesarean section rate by more than $50 \%[10,11]$.

Another study revealed that there were no significant differences in the duration of labor, rate of instrumental vaginal delivery or emergency cesarean section, or neonatal outcome in laboring mothers who did or did not receive combined spinal epidural for labor analgesia. Epidural analgesia had no influence on the risk of caesarean section or long-term back pain, and did not appear to have an immediate effect on neonatal outcome as determined by APGAR (Appearance, Pulse, Grimace, Activity and Respiration) scores or admission to neonatal intensive care $[12,13]$. 
This labor pain management practice is good in developed countries but poor in third world countries such as countries in Africa [5]. This is because pregnant women in developing countries are often unaware that such pain treatment is available, which leads to low demand for the service and for analgesia such as an epidural. In Africa, access to knowledge and the availability of medical care can influence attitudes towards pain relief, and women may not even know that labor pain can be relieved [5, 14].

Lack of awareness among pregnant women is an important reason for not utilizing analgesic techniques, and women suffer from the agony of labor pain because of lack of awareness, unbound fears and limited knowledge about the availability of analgesia service [3, 15]. A study in India showed that $50 \%$ of caesarean delivery was as a result of maternal request due to their previous bad experiences with labor pain [15].

Analgesia for labor is widely utilized in highincome countries, but this is not the case for Africa. Issues in high-income countries are focused on the choice of methods and complications, while in developing countries, the issue revolves around awareness, acceptability and availability of analgesia for labor [16]. During pregnancy, women should be told about the benefits and potential adverse effects of the different methods of pain control [17].

In Ethiopia, according to the standard of midwifery care practice in 2013 by the Ethiopian Federal Ministry of Health (EFMOH), provision of physical and psychological support and use of pharmacological and non-pharmacological comfort measures during labor and birth are listed as core competencies under practice standard III. However, despite its recognition as a critical component in the $\mathrm{EFMOH}$ efforts to improve the quality of maternal health services, its practice is not noticeably acknowledged [9].

The American College of Obstetricians and Gynecologists (ACOG) recommends that pain management be provided whenever medically indicated during labor. In the absence of a medical contraindication, maternal request is a sufficient medical indication for pain relief during labor [8].
As the experience of pain in labor is subjective and differs from woman to woman, all women should have a choice according to their preference and individual circumstances. A lack of awareness and misunderstanding regarding the acceptability, safety and availability of pain relief options were found to be the main reasons that women in many low- and middle-income countries did not received adequate pain relief [18].

Labor analgesia is not routinely practiced in developing countries. The reasons include the lack of demand by patients, obstetricians and anesthesiologists who are not keen to routinely practice it, lack of equipment/devices and low awareness among pregnant women [5].

In order to achieve good labor pain management, collaboration between the obstetrician, anesthetist and the pregnant woman is needed. The findings of this study may remind clinicians of the importance of educating mothers about labor analgesia. In addition, the baseline data in this study could open the door to further research activity. Finally, an overview of awareness, attitude and demand for labor analgesia among pregnant women could be a clue for hospital administrators and policymakers for planning and intervening in areas of deficit, thereby organizing and equipping the health institutions in ways to improve the quality of care. As far as we know, there are no studies conducted in Ethiopia among pregnant women regarding their awareness, attitude and desire for labor analgesia. Therefore, this study aimed to assess the awareness, attitude and desire for labor analgesia among pregnant women at the University of Gondar Comprehensive Specialized Hospital.

\section{METHODS}

\section{Study Design and Period}

A cross-sectional study was conducted from February to March 2019. 


\section{Study Area}

This study was conducted at the University of Gondar Comprehensive Specialized Hospital outpatient department and included pregnant women who visited the department for antenatal care. The University of Gondar is located in Gondar town, which is about $738 \mathrm{~km}$ from Addis Ababa, Northwest Ethiopia.

\section{Source and Study Population}

\section{Source Population}

All pregnant women who visited the University of Gondar Comprehensive Specialized Referral Hospital.

\section{Study Population}

All pregnant women who visited for antenatal care at the University of Gondar Comprehensive Specialized Hospital during the study period.

\section{Inclusion and Exclusion Criteria}

\section{Inclusion Criteria}

All pregnant women who visited for antenatal care at the University of Gondar Comprehensive Specialized Hospital during the study period and agreed to participate in the study were included.

\section{Exclusion Criteria}

Pregnant women who did not volunteer to participate, age $<18$ years and pregnant women who had difficulty communicating were excluded.

\section{Study Variables}

\section{Dependent Variables}

Awareness of labor analgesia. Attitude towards labor analgesia. Desire for labor analgesia.

\section{Independent Variables}

Sociodemographic factors: Age, religion, profession, level of education, residence, culture.
Obstetric factors: Parity, mode of previous delivery, place of previous delivery.

\section{Sample Size Determination}

To determine the sample size, a single population proportion formula was used based on a study done in Kenya, which found that $56 \%$ of the participants had awareness of labor pain relief methods. Considering this, with 95\% confidence and 5\% margin of error, the sample size was determined [19]:

$$
\begin{gathered}
\quad N=(Z \alpha / 2) 2 p(1-p) / d 2 \\
\begin{array}{c}
N=(1.96) 2) 0.56(0.44) /(0.05) 2 \Rightarrow 378.628 \\
=379 .
\end{array}
\end{gathered}
$$

By considering $10 \%$ non-response rate, the final sample size was 417 .

\section{Sampling Technique and Procedure}

Convenience sampling was used to select study participants by taking every consecutive pregnant woman until the required sample size was reached.

\section{Operational Definitions}

Parity: Women who had not delivered before were considered nulliparous, and women who had delivered at least once were considered parous [4].

Had awareness: Women who said yes when asked if they had prior information about labor analgesia [16].

Had good attitude: Women who said yes when asked if labor pain should be treated [16, 20].

Good desire: Women who said yes when asked if they desired labor analgesia for their next delivery [15].

\section{Data Collection Procedure}

Data were collected using a questionnaire prepared from previous literature regarding awareness, attitude and desire for labor analgesia. One 
person collected the data and one experienced person supervised the data collection. The questionnaire was written in Amharic to collect data from the pregnant women. The study participants were selected consecutively.

\section{Data Quality Control}

To ensure quality of data, pre-testing of the data collection tool was conducted on 20 pregnant women who were not included in the main study. Based on the findings, possible amendments were made to the questionnaire. Training and orientation were given to the selected data collectors by the principal investigator for one day regarding the aim of the study, how to approach study subjects, how to use the questionnaire and how to collect the data. The principal investigator and supervisor checked the collected data for completeness, accuracy and clarity. Incomplete data were discarded and counted as non-responses. Daily supervision and feedback were provided by the principal investigator during the data collection period. Finally, coding, data entry, data cleaning and crosschecking were done before data analysis.

\section{Data Analysis and Interpretation}

After data collection, the data were coded, entered and cleaned before statistical tests. EpiData 4.2 and SPSS version 20 software were used for data entry and analysis, respectively. Descriptive statistics were carried out and the results were presented using text, tables and graphs. Both bivariable and multivariable binary logistic regression analysis were used to identify factors associated with awareness, attitude and desire among pregnant mothers. Variables with a $p$ value less than $<0.2$ in the bivariable analysis were fitted into the multivariable logistic regression analysis. Both crude odds ratio (COR) and adjusted odds ratio (AOR) with their corresponding 95\% confidence intervals were calculated to show the strength of association. In multivariable analysis, variables with a $p$ value of $<0.05$ were considered statistically significant. The Hosmer-Lemeshow test was also used for checking goodness of fit.

\section{Compliance with Ethics Guidelines}

This study was approved by the ethics committee of the University of Gondar Comprehensive Specialized Hospital and was performed in accordance with the Helsinki Declaration of 1964 and its later amendments. Informed written consent was obtained from each study subject after clear explanation about the objective and purposes of the study. Participants were informed of their right to refuse to participate in the study at any time. Confidentiality was ensured by avoiding personal identification on questionnaires and by keeping the questionnaires locked.

\section{RESULTS}

\section{Sociodemographic Characteristics of Study Participants}

A total of 417 questionnaires were collected, from which we included 410 participants, yielding a response rate of $98.32 \%$. Seven questionnaires were excluded from the analysis due to incompleteness. Greater than half $(53.2 \%)$ of the subjects were in the age group of 25-31 years. A majority (71.5\%) of the participants were orthodox. Less than half $(46.8 \%)$ of the subjects had graduated from school, and $26.3 \%$ had attended secondary school. Almost equal numbers of subjects were housewives (33.4\%) and government employees (33.9\%). More than half of the women lived in urban areas $(79.3 \%)$ (Table 1$)$.

\section{Obstetric Characteristics of the Study Participants}

The majority of women were parous $(63.7 \%)$. Regarding previous mode of delivery, $82 \%$ had delivered vaginally. Most of the women delivered at the national referral hospital (70.9\%) (Table 2). 
Table 1 Sociodemographic characteristics of pregnant women who visited the antenatal care facility at the University of Gondar Comprehensive Specialized Hospital, Northwest Ethiopia, February-March 2019

\begin{tabular}{|c|c|c|}
\hline Variable & $\begin{array}{l}\text { Frequency } \\
(n)\end{array}$ & $\begin{array}{l}\text { Percentage } \\
(\%)\end{array}$ \\
\hline \multicolumn{3}{|l|}{ Age in years } \\
\hline $18-24$ & 111 & 27.1 \\
\hline $25-31$ & 218 & 53.2 \\
\hline$>31$ & 81 & 19.8 \\
\hline \multicolumn{3}{|l|}{ Religion } \\
\hline Orthodox & 293 & 71.5 \\
\hline Muslim & 90 & 22.0 \\
\hline Protestant & 27 & 6.5 \\
\hline \multicolumn{3}{|l|}{ Educational status } \\
\hline $\begin{array}{l}\text { Unable to read and } \\
\text { write }\end{array}$ & 59 & 14.4 \\
\hline Can read and write & 14 & 3.4 \\
\hline Primary & 37 & 9 \\
\hline Secondary & 108 & 26.3 \\
\hline Graduated & 192 & 46.8 \\
\hline \multicolumn{3}{|l|}{ Occupation } \\
\hline Housewife & 137 & 33.4 \\
\hline Merchant & 91 & 22.2 \\
\hline Government employee & 139 & 33.9 \\
\hline Farmer & 43 & 10.5 \\
\hline \multicolumn{3}{|l|}{ Residence } \\
\hline Rural & 85 & 20.7 \\
\hline Urban & 325 & 79.3 \\
\hline \multicolumn{3}{|l|}{ Ethnicity } \\
\hline Amhara & 402 & 98.05 \\
\hline Tigray & 3 & 0.73 \\
\hline Oromo & 4 & 0.97 \\
\hline Gurage & 1 & 0.24 \\
\hline
\end{tabular}

Table 2 Obstetric characteristics of pregnant women who visited the antenatal care facility at the University of Gondar Comprehensive Specialized Hospital, Northwest Ethiopia, February-March 2019

\begin{tabular}{lcl}
\hline Variable & $\begin{array}{l}\text { Frequency } \\
(n)\end{array}$ & $\begin{array}{l}\text { Percentage } \\
(\%)\end{array}$ \\
\hline Partial status $(n=410)$ & & 36.3 \\
Nulliparous & 149 & 63.7 \\
Parous & 261 & \\
Mode of pervious delivery $(n=261)$ & 82 \\
Normal & 214 & 18 \\
Cesarean section & 47 & \\
Place of previous delivery $(n=261)$ & 11.9 \\
At home & 31 & 17.2 \\
At health center & 45 & 70.9 \\
At national referral & 185 & \\
hospital & & \\
Gestational age in weeks $(n=410)$ & 2.9 \\
$1-12$ & 2 & 44.6 \\
$13-28$ & 183 & 52.4 \\
$>29$ & 215 & \\
\hline
\end{tabular}

\section{Awareness of Labor Analgesia}

Out of 410 pregnant women, only 33 (8\%) were aware of labor analgesia. Most of these women received information about labor analgesia from a health care provider $(9,27.3 \%)$ or from friends or relatives $(8,24.2 \%)$, and of the women who were aware of labor analgesia, the majority were aware of injections in the lower back (14, $42.4 \%)$. Twenty women $(60.6 \%)$ had heard about labor analgesia during their current pregnancy. Out of 33, only $3(9.1 \%)$ had previous experience with labor analgesia (Table 3 ).

\section{Attitude and Labor Pain Expectation and Experience}

Regarding expectation of labor pain among 149 nulliparous women, $91.9 \%$ expected labor to be 
Table 3 Awareness of labor analgesia among pregnant women who visited the antenatal care facility at the University of Gondar Comprehensive Specialized Hospital, Northwest Ethiopia, February-March 2019

\begin{tabular}{lll}
\hline Questions & Frequency & Percentage \\
$(n)$ & $(\%)$ \\
\hline
\end{tabular}

Do you have information about labor analgesia? $(n=410)$

$\begin{array}{ccc}\text { Yes } & 33 & 8 \\ \text { No } & 377 & 92\end{array}$

Information obtained from $(n=33)$

\begin{tabular}{|c|c|c|}
\hline The media or reading & 5 & 15.2 \\
\hline Antenatal talks in the & 7 & 21.2 \\
\hline hospital/maternal and child & 8 & 24.2 \\
\hline nealth clinics & 4 & 12.1 \\
\hline Friends or relatives & 9 & 27.3 \\
\hline
\end{tabular}

Health care provider

Methods of pain relief you heard about $(n=33)$

\begin{tabular}{|c|c|c|}
\hline Inhaled analgesia & 0 & 0 \\
\hline Intravenous pethidine or & 6 & 18.2 \\
\hline morphine & 11 & 33.3 \\
\hline Intramuscular injection in & 14 & 42.4 \\
\hline $\begin{array}{l}\text { the thigh, shoulder and } \\
\text { buttock }\end{array}$ & 2 & 6.1 \\
\hline
\end{tabular}

Injection in the lower back

(epidural, spinal)

Massage, deep breathing and

similar reassurance

When did you hear about pain relief? $(n=33)$

$\begin{array}{lll}\text { During current pregnancy } & 20 & 60.6 \\ \text { During previous pregnancy } & 9 & 27.3 \\ \text { During previous child birth } & 4 & 12.1 \\ \text { Experience of pain relief methods }(n=33) & \\ \text { Yes } & 3 & 9.1 \\ \text { No } & 30 & 90.9\end{array}$

Which type of analgesia have you used before? $(n=3)$
Table 3 continued

\begin{tabular}{lll}
\hline Questions & $\begin{array}{l}\text { Frequency } \\
(\boldsymbol{n})\end{array}$ & $\begin{array}{l}\text { Percentage } \\
(\%)\end{array}$ \\
\hline IM pethidine, diclofenac & 1 & 33.33 \\
IV pethidine or tramadol & 1 & 33.33 \\
Massage, deep breathing & 0 & 0 \\
Epidural analgesia & 1 & 33.3 \\
Other (unspecified) & 0 & 0 \\
\hline
\end{tabular}

$I M$ intramuscular, $I V$ intravenous

painful. Of those who said labor pain is painful, $75.2 \%$ described labor pain as severe and $21.9 \%$ described it as moderate. Out of those who had previously experienced labor $(n=261), 197$ $(75.5 \%)$ described labor pain as severe and $23.4 \%$ described it as moderate. Regarding attitudes, $74.1 \%$ of the participants felt that labor should be pain-free (Table 4 ).

\section{Desire for Labor Analgesia Among Pregnant Women}

The majority (65.9\%) of pregnant women wanted labor analgesia for their next delivery. Regarding their preferred methods of analgesia for the next delivery, the majority of the pregnant women said that they would do as the doctor advised (76\%) (Fig. 1). Among the 34.1\% of women who refused labor analgesia for their next delivery, the commonest reasons were that it was against the will of God (35\%) or that they wanted to experience natural child birth (27\%) (Fig. 2).

\section{Factors Associated with Awareness of Labor Analgesia}

The likelihood of having awareness of labor analgesia was 7.227 times (AOR: 7.227, 95\%, CI 2.406-21.720) greater among parous mothers as compared to nulliparous mothers. The odds of having awareness of labor analgesia were 3.133 
Table 4 Pain expectation, experience and attitude among pregnant women receiving antenatal care (ANC) at the University of Gondar Comprehensive Specialized Hospital, Northwest Ethiopia, February-March 2019

\begin{tabular}{lll}
\hline Variable & Frequency $(n)$ & Percentage (\%) \\
\hline $\begin{array}{l}\text { What is your expectation (for nulliparous women)? } \\
(n=149)\end{array}$ & \multicolumn{1}{l}{ ? } \\
No idea & 12 & 0 \\
Pain-free & 0 & 91.9 \\
Painful & 137 & 2.9 \\
Mild & 4 & 21.9 \\
Moderate & 30 & 75.2 \\
Severe & 103 & 0 \\
On which scale do you categorize labor pain [for those \\
with previous experience]? $(n=261)$ \\
Pain-free & 0 & 1.1 \\
Mild pain & 3 & 23.4 \\
Moderate pain & 61 & 75.5 \\
Severe pain & 197 & 74.1 \\
Do you believe labor pain should be managed? $(n=410)$ \\
Yes & 304 & 25.9 \\
No & 106 & \\
\hline
\end{tabular}

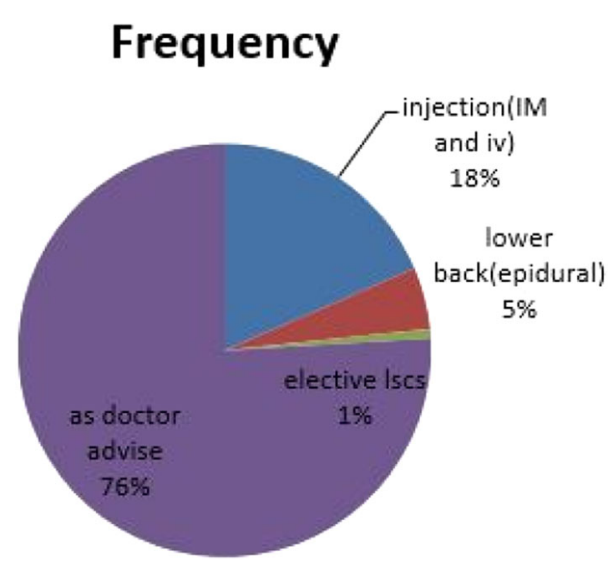

Fig. 1 Preferred methods of labor analgesia for the next delivery among pregnant women receiving ANC at the University of Gondar Comprehensive Specialized Hospital, Northwest Ethiopia, February-March 2019

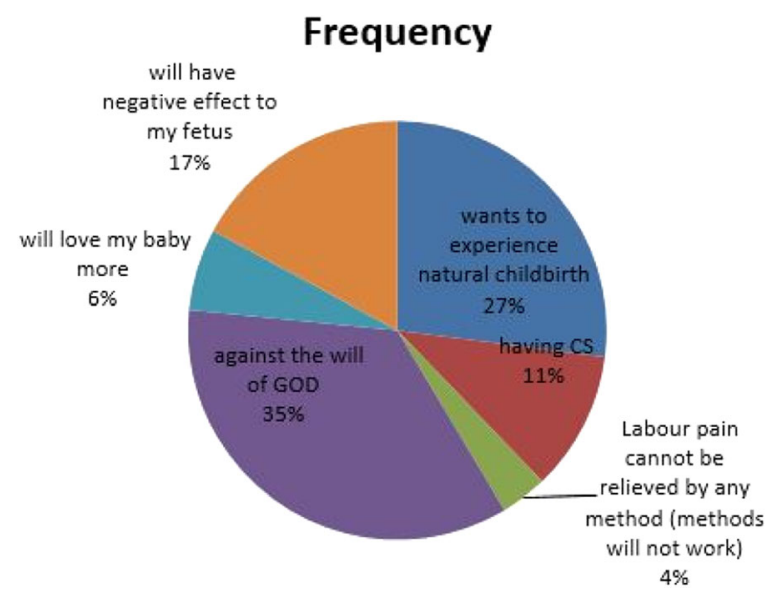

Fig. 2 Reason for refusal of labor analgesia for the next delivery among pregnant women receiving ANC at the University of Gondar Comprehensive Specialized Hospital, Northwest Ethiopia, February-March 2019

times (AOR: 3.133, 95\% CI 1.144-8.581) more than among government employees as compared to housewives (Table 5).

\section{Factors Associated with Attitude Towards Labor Analgesia}

Housewives as compared to farmers were 3.539 times more likely to believe in labor pain treatments (AOR: 3.539, 95\% CI 1.372-9.131). Similarly, merchants were 7.757 times (AOR: 7.757, 95\% CI 2.425-24.808) more likely believe that labor pain should be treated. The odds of having a good attitude towards labor analgesia were 6.488 times (AOR: 6.488, 95\% CI 1.894-22.227) higher in government employees as compared to farmers (Table 6).

\section{Factors Associated with Desire for Labor Analgesia}

Women in the age group of 25-31 were 1.815 times more likely to want labor analgesia for their next delivery (AOR: 1.815, 95\% CI 1.103-2.989) (Table 7). 
Table 5 Factors associated with awareness of labor analgesia among pregnant women receiving antenatal care at the University of Gondar Comprehensive Specialized Hospital, Northwest Ethiopia, February-March 2019

\begin{tabular}{llllll}
\hline Variable & $\begin{array}{l}\text { Awareness status (yes) } \\
\text { no) }\end{array}$ & $\begin{array}{l}\text { Percentage } \\
(\%)\end{array}$ & COR (95\% CI) & AOR & $p$ value \\
\hline Parity & & & & & \\
Nulliparous (1) & $4 / 145$ & 2.75 & 1 & 1 & $0.001^{* *}$ \\
Parous & $29 / 232$ & 12.5 & $4.531(1.56-13.1)$ & 7.227 & $(2.405-21.720)$ \\
& & & & & \\
Profession & & & & 1 & 0.794 \\
Housewife $(1)$ & $6 / 131$ & 4.58 & 1 & $1.21(0.369-3.962)$ & $0.007^{*}$ \\
Merchant & $6 / 85$ & 7.058 & 1.541 & $(0.481-4.939)$ & 3.935 \\
Government & $19 / 120$ & 15.83 & 3.457 & $(1.461-10.602)$ \\
employee & $2 / 41$ & 4.87 & $(1.336-8.495)$ & 3.405 & 0.27 \\
Farmer & & & 1.065 & $(0.301-38.545)$
\end{tabular}

$C O R$ crude odds ratio, $A O R$ adjusted odds ratio

${ }^{* *}$ Very significant, ${ }^{*}$ significant; $1=$ reference $=$ housewife and nulliparous

Table 6 Factors associated with attitude towards labor analgesia among pregnant women receiving antenatal care at the University of Gondar Comprehensive Specialized Hospital, Northwest Ethiopia, February-March 2019

\begin{tabular}{|c|c|c|c|c|c|}
\hline \multirow[t]{2}{*}{ Variable $(n=410)$} & \multicolumn{2}{|c|}{ Attitude status } & \multirow[t]{2}{*}{$\operatorname{COR}(95 \% \mathrm{CI}) p$ value } & \multirow[t]{2}{*}{$\operatorname{AOR}(95 \% \mathrm{CI})$} & \multirow[t]{2}{*}{$p$ value } \\
\hline & Yes & No & & & \\
\hline \multicolumn{6}{|l|}{ Profession } \\
\hline Housewife & 96 & 41 & $2.693(1.334-5.433)$ & $3.539(1.372-9.131)$ & $0.009^{*}$ \\
\hline Merchant & 76 & 15 & $5.827(2.577-13.176)$ & $7.757(2.425-24.808)$ & $0.001^{*}$ \\
\hline Government employee & 112 & 27 & $4.77(2.295-9.918)$ & $6.488(1.894-22.227)$ & $0.003^{*}$ \\
\hline Farmer (1) & 20 & 23 & 1 & 1 & \\
\hline
\end{tabular}

$C O R$ crude odds ratio, $A O R$ adjusted odds ratio

*Significant; 1 , reference $=$ farmer

Obstetric Characteristics and CrossTabulation with Awareness, Attitude and Desire for Labor Analgesia

Among women with awareness of labor analgesia, $87.9 \%$ were parous, $82.5 \%$ had a normal delivery (spontaneous vaginal birth) and 96.6\% delivered at a national referral hospital. Regarding mothers who had a good attitude towards labor analgesia, $64.1 \%$ were parous, $77.9 \%$ delivered by spontaneous vaginal delivery (SVD) and $75.4 \%$ delivered at a national 
Table 7 Factors associated with desire for labor analgesia among pregnant women receiving antenatal care at the University of Gondar Comprehensive Specialized Hospital, Northwest Ethiopia, and February-March 2019

\begin{tabular}{|c|c|c|c|c|c|}
\hline \multirow{2}{*}{$\begin{array}{l}\text { Variable } \\
\text { Age }\end{array}$} & \multicolumn{2}{|c|}{ Desire status $n=410$} & \multirow[t]{2}{*}{ COR $(95 \% \mathrm{CI})$} & \multirow[t]{2}{*}{ AOR (95\% CI) } & \multirow[t]{2}{*}{$p$ value } \\
\hline & Yes & No & & & \\
\hline $18-24(1)$ & $63(56.8 \%)$ & $48(43.2 \%)$ & 1 & 1 & $0.019^{*}$ \\
\hline $25-31$ & $155(71.1 \%)$ & $63(28.9 \%)$ & $1.875(1.164-3.018)$ & $1.815(1.103-2.989)$ & 0.207 \\
\hline$>31$ & $52(64.2 \%)$ & $29(35.8 \%)$ & $1.366(0.758(2.463)$ & $1.518(0.794-2.902)$ & \\
\hline
\end{tabular}

$C O R$ crude odds ratio, $A O R$ adjusted odds ratio

*Significant, reference age group (18-24)

Table 8 Obstetric variables and their cross-tabulation for awareness, attitude and desire for labor analgesia among pregnant women receiving antenatal care at the University of Gondar Comprehensive Specialized Hospital, Northwest Ethiopia, February-March 2019

\begin{tabular}{|c|c|c|c|c|c|c|}
\hline \multirow[t]{2}{*}{ Variable } & \multicolumn{2}{|c|}{ Awareness status } & \multicolumn{2}{|c|}{ Attitude status } & \multicolumn{2}{|l|}{ Desire status } \\
\hline & $\overline{\text { Yes }}$ & No & $\overline{\text { Yes }}$ & No & $\overline{\text { Yes }}$ & No \\
\hline \multicolumn{7}{|l|}{ Parity $(n=410)$} \\
\hline Nulliparous & $4(12.1 \%)$ & $145(38.5 \%)$ & $109(35.9 \%)$ & $40(37.7 \%)$ & $103(38.1 \%)$ & $46(32.9 \%)$ \\
\hline Parous & $29(87.9 \%)$ & $232(61.5 \%)$ & $195(64.1 \%)$ & $66(64.1 \%)$ & $167(61.9 \%)$ & $94(67.1 \%)$ \\
\hline \multicolumn{7}{|c|}{ Mode of delivery $(n=261)$} \\
\hline Normal (vaginal) & $24(82.8 \%)$ & $190(81.9 \%)$ & $152(77.9 \%)$ & $62(93.9 \%)$ & $135(80.8 \%)$ & $79(84 \%)$ \\
\hline CS & $5(17.2 \%)$ & $42(18.1 \%)$ & $43(22.1 \%)$ & $4(6.1 \%)$ & $32(19.2 \%)$ & $15(16 \%)$ \\
\hline \multicolumn{7}{|c|}{ Place of delivery $(n=261)$} \\
\hline At home & $0(0 \%)$ & $31(13.4 \%)$ & $14(7.2 \%)$ & $17(25.8 \%)$ & $15(9 \%)$ & $16(17 \%)$ \\
\hline At health center & $1(3.4 \%)$ & $44(19 \%)$ & $34(17.4 \%)$ & $11(16.7 \%)$ & $29(17.4 \%)$ & $16(17 \%)$ \\
\hline At referral hospital & $28(96.6 \%)$ & $157(67.7 \%)$ & $147(75.4 \%)$ & $38(57.6 \%)$ & $123(73.7 \%)$ & $62(66 \%)$ \\
\hline
\end{tabular}

Parity = for all pregnant women; mode of delivery and place of delivery only for parous women

referral hospital. Among mothers who wanted labor analgesia for their next delivery, $61.9 \%$ were parous, $80.8 \%$ delivered by SVD and $73.7 \%$ delivered at a referral hospital (Table 8).

\section{DISCUSSION}

In this study, the awareness of labor analgesia was low (8\%) (95\% CI 5.6-10.7). In developing countries, pain associated with childbirth is often considered natural. The idea of abolishing labor pain with medicines seems unnecessary or against traditional values. The aim of this study was to highlight the awareness, attitude and desire of pregnant women towards labor analgesia. The result of this study was comparable to studies done by Nabukenya (7\%), Naithani et al. $(9.5 \%)$ and Prakash et al. (7.14\%) [15, 16, 21]. 
The level of awareness in the present study was low as compared with studies by Mugambe et al. (56.3\%), Minhas et al. (76\%) and Karuga et al. $(56 \%)[14,19,22]$. The reason for this might be that the study population was well educated in the research by Karuga et al. and Minhas et al. This discrepancy in the level of awareness can be attributed to the fact that childbirth was still viewed as a physiological process among our participants, which might be due to lack of education during antenatal visits.

The majority (74.1\%) (95\% CI 69.5-78.3) of participants felt that labor should be pain-free; this percentage was lower than that in a study done in Uganda (87.8\%) [16], but higher than studies in South Africa (48.3\%) [12]. Regarding the expectation of labor pain, out of 149 nulliparous mothers, $91.9 \%$ said that labor was painful and $8.1 \%$ said they had no idea about labor pain, which was in line with a study done in India, showing $87 \%$ and $7.5 \%$, respectively [20]. Of those who said labor pain was painful, $77.1 \%$ said that labor pain was severe. Among those who had previously experienced labor $(n=261), 75.5 \%$ (95\% CI 70.1-80.8) described labor pain as severe, which was higher than in a study by Mungayi et al. (66. 7\%) [23].

Although awareness of painless labor was low, the majority (65.9\% (95\% CI 61.2-70.2\%) of participants said they wanted to have labor analgesia for their next delivery. This was lower than studies in Uganda (87.7\%) and in Nepal $(72.2 \%)[16,24]$, but higher than studies by Prakash et al. (16.43\%) [15] and Yadav et al. (13.5\%) [25]. The most common reason given by women for not selecting labor analgesia for their next delivery was that it was against the will of God (35\%). This was in contrast to studies by Naithani et al., Olayemi et al., Prakash et al. and Nabukenya et al., which all showed that the commonest reason for refusal was a desire to experience natural childbirth (45\% and above) $[15,16,21,26]$. This may be because our participants were highly adherent to their religion.

Regarding the source of information about labor analgesia, the present study showed that most participants got information about labor analgesia from health care providers $(27.3 \%)$ and friends and relatives $(24.2 \%)$. This is in contrast to the study in Uganda, where the majority (47\%) got their information from friends or family and $26 \%$ from previous labor, and was also different from a South African study, in which women had gained information from previous experience $(56.5 \%)$ or from friends and relatives $(55.3 \%)[14,16]$. The reason may be that our participants found good sociocultural value in discussing and sharing things with their friends and families and had high trust in their health care provider. Among those who had awareness, $60.6 \%$ heard about labor analgesia during their current pregnancy, which was low as compared to the study by Prakash et al. (80\%) [15].

Regarding the pain relief methods, most of the participants said that they had information about injections (42.4\%) in the lower back, either spinal or epidural, and this was in line with results from a South African study (32.9\%) but higher than a study in Nigeria which showed that $10 \%$ were aware of an injection in the back (epidural) [27]. Of the participants, $33.3 \%$ heard about intramuscular injection, which was low compared to results from a study in South Africa (65.9\%) [14]. A study in Nigeria found that only $10 \%$ were aware of injection in the back (epidural) [26].

The present study showed a significant association with awareness of labor analgesia among parous (AOR: 7.227, 95\% CI 2.406-21.720) compared to nulliparous women, which was contrary to the study by Naithani et al. [21]. This could be because parous mothers had experience with labor pain, which in turn led them to search for information about labor analgesia. Government employees (AOR: 3.133, 95\% CI 1.144-8.581) compared to housewives had a significant association with awareness of labor analgesia, and this was similar to the study by Minhas et al. [22]. This may be because government employees had the opportunity to obtain information from their workplace, while housewives did not.

This study also revealed that awareness about labor analgesia had no association with educational status, and this was congruent with a study by Deogaonkar et al. [28]. This indicates that there was a low level of awareness in all strata of education. Age and religion had no 
association with awareness, which was in line with the study by Naithani et al. [21].

In this study there was a significant association between occupation and attitude of women towards labor analgesia; housewives (AOR: 3.539, 95\% CI 1.372-9.131), merchants (AOR: 7.757, 95\% CI 2.425-24.808) and government employees (AOR: 6.488, 95\% CI 1.894-22.227) were more likely to believe that labor pain should be treated. No other studies have shown an association with occupation and attitude. The reason behind this might be the cultural belief among farmers that an inability to tolerate labor pain is a sign of emotional weakness, and that women should cope with labor pain, while those in other professions might not feel this way, even if this is not supported by evidence.

In this study there was no association between education or parity, with acceptance of labor analgesia similar to studies in India by Shidhaye et al. and Yadav et al. [25, 27]. This might be explained by the fact that most mothers wanted labor analgesia for their next delivery, so there would be no difference between education level or parity.

In studies by Nabukenya et al. and Prakash et al., multiparity was positively associated with acceptance of labor analgesia, in contrast to the present study, which showed no association between parity and desire (acceptance) for labor analgesia $[15,16]$.

No association was found between age and acceptance in studies by Nabukenya et al. [16] and Shidhaye et al. [27], whereas the present study revealed an association between desire for labor analgesia and the age group 25-31 (AOR: $1.815,95 \%$ CI $1.103-2.989$ ) as compared to ages $18-24$. This is in contrast to the study by Olayemi et al., who found that age was negatively correlated [26], but congruent with the study by Gari et al. [29]. This might be because women aged 25-31 had a better level of understanding things than their counterparts.

\section{Limitations}

Finally, this study excluded mothers who were in labor, which may have had an effect on demanding labor analgesia. This study did not use standardized validated questionnaire tools. The study is also based on a questionnaire that was translated by investigators, which may have had an effect on the answer pattern by the participants.

\section{CONCLUSION}

The awareness of labor analgesia among pregnant women was low in the University of Gondar Comprehensive Specialized Hospital. There is a need for teamwork by all stakeholders in health sectors to improve attitudes towards and increase the awareness of and desire for of labor analgesia among pregnant women receiving antenatal care.

\section{ACKNOWLEDGEMENTS}

We thank the participants of the study.

Funding. No funding or sponsorship was received for this study or publication of this article.

Authorship. All named authors meet the International Committee of Medical Journal Editors (ICMJE) criteria for authorship for this article, take responsibility for the integrity of the work as a whole, and have given their approval for this version to be published.

Disclosures. Misganaw Mengie Workie, Wubie Birlie Chekol, Demeke Yilkal Fentie, Seid Adem Ahmed and Yosef Belay Bizuneh have nothing to disclose.

Compliance with Ethics Guidelines. This study was approved by the ethics committee of the University of Gondar Comprehensive Specialized Hospital and was performed in accordance with the Helsinki Declaration of 1964 and its later amendments. Written informed consent was obtained from each study subject after clear explanation about the objective and purposes of the study. Participants were informed of their right to refuse to participate in 
the study at any time. Confidentiality was ensured by avoiding personal identification on questionnaires and by keeping the questionnaires locked.

Data Availability. The data sets used and analyzed during the study are available from the corresponding author on reasonable request.

Open Access. This article is licensed under a Creative Commons Attribution-NonCommercial 4.0 International License, which permits any non-commercial use, sharing, adaptation, distribution and reproduction in any medium or format, as long as you give appropriate credit to the original author(s) and the source, provide a link to the Creative Commons licence, and indicate if changes were made. The images or other third party material in this article are included in the article's Creative Commons licence, unless indicated otherwise in a credit line to the material. If material is not included in the article's Creative Commons licence and your intended use is not permitted by statutory regulation or exceeds the permitted use, you will need to obtain permission directly from the copyright holder. To view a copy of this licence, visit http://creativecommons.org/licenses/by$\mathrm{nc} / 4.0 /$.

\section{REFERENCES}

1. Barakzai A, Haider G, Yousuf F, Haider A, Muhammad N. Awareness of women regarding analgesia during labour. J Ayub Med Coll Abbottabad. 2010;22(1):73-5.

2. Ramasamy P. Knowledge, attitude, practice and barriers to educational implementation of nonpharmacological pain management during labor in Selected Hospitals, Kenya. Cent Afr J Public Health. 2018;4(1):20.

3. Poomalar K, Sameera L. Awareness of labour analgesia among antenatal women in semi urban area. Int J Reprod Contracept Obstet Gynecol. 2016;5: 2612-7.

4. Wong CA. Advances in labor analgesia. Int J Womens Health. 2010;9(1):139-54.
5. Karn S, Yu H, Karna S, Chen L, Qiao D. Women's awareness and attitudes towards labor analgesia influencing practice between developed and developing countries. Adv Reprod Sci. 2016;4(2):46.

6. Affonso DD, De AK, Horowitz JA, Mayberry LJ. An international study exploring levels of postpartum depressive symptomatology. J Psychosom Res. 2000;49(3):207-16.

7. Gausia K, Ryder D, Ali M, Fisher C, Moran A, Koblinsky M. Obstetric complications and psychological well-being: experiences of Bangladeshi women during pregnancy and childbirth. J Health Popul Nutr. 2012;30(2):172-80.

8. American College of Obstetricians and Gynecologists Committee on Practice Bulletins-Gynecology, ACGO practice Bulletin. Clinical management guidelines for obstetrician Gynecologists. Medical management of abortion. Obstet Gynecol. 2001;97(4):1-13.

9. Health FDR of EM of. Health Sector Development Program IV, 2010/11-2014/15. Ministry of Health Addis Ababa; 2010.

10. Cheng YW, Shaffer BL, Nicholson JM, Caughey AB. Second stage of labor and epidural use: a larger effect than previously suggested. Obstet Gynecol. 2014;123(3):527-35.

11. Liu EHC, Sia ATH. Rates of caesarean section and instrumental vaginal delivery in nulliparous women after low concentration epidural infusions or opioid analgesia: systematic review. BMJ. 2004;328(7453):1410.

12. Singh SKSC, Yahya N, Misiran K, Masdar A, Nor NM, Yee LC. Combined spinal-epidural analgesia in labour: its effects on delivery outcome. Braz J Anesthesiol Engl Ed. 2016;66(3):259-64.

13. Anim-Somuah M, Smyth RMD, Cyna AM, Cuthbert A. Epidural versus non-epidural or no analgesia for pain management in labour. Cochrane Database Syst Rev. 2018. https://doi.org/10.1002/14651858. CD000331.pub4.

14. Mugambe J, Nel M, Hiemstra L, Steinberg W. Knowledge of and attitude towards pain relief during labour of women attending the antenatal clinic of Cecilia Makiwane Hospital, South Africa. South Afr Fam Pract. 2007;49(4):16-16d.

15. Prakash A, Yadav A, Karim H, Sahoo S, Jena P, Aman $\mathrm{K}$. Knowledge, awareness and acceptance of labor analgesia among antenatal women in a Remote Island: a questionnaire based study. Br J Med Med Res. 2017;21(10):1-7. 
16. Nabukenya MT, Kintu A, Wabule A, Muyingo MT, Kwizera A. Knowledge, attitudes and use of labour analgesia among women at a low-income country antenatal clinic. BMC Anesthesiol. 2015;15(1):98.

17. Jones L, Othman M, Dowswell T, Alfirevic Z, Gates $S$, Newburn M, et al. Pain management for women in labour: an overview of systematic reviews. Cochrane Database Syst Rev. 2012;2012(3): CD009234. https://doi.org/10.1002/14651858. CD009234.pub2 (Published 2012 Mar 14).

18. McCauley M, Stewart C, Kebede B. A survey of healthcare providers' knowledge and attitudes regarding pain relief in labor for women in Ethiopia. BMC Pregnancy Childbirth. 2017;17(1):56.

19. Karuga R, Nekyon D, Mung'ayi V. Knowledge, attitude and use of labour pain relief methods among women attending antenatal clinic in Nairobi. East Afr Med J. 2008;85(9):438.

20. Kapadia S, Parmar K, Solanki N, Patadia K. Knowledge, awareness and attitude of antenatal women towards labor pain and labor pain relief. BJKines. 2013;5(1):11-4.

21. Naithani U, Bharwal P, Chauhan SS, Kumar D, Gupta S. Knowledge, attitude and acceptance of antenatal women toward labor analgesia and caesarean section in a medical college hospital in India. J Obstet Anaesth Crit Care. 2011;1(1):13.

22. Minhas MR, Kamal R, Afshan G, Raheel H. Knowledge, attitude and practice of parturients regarding epidural analgesia for labour in a university hospital in Karachi. J Pak Med Assoc. 2005;55(2):63-6.
23. Mungayi V, Nekyon D, Karuga R. Knowledge attitude and use of labour pain relief methods among women attending antenatal clinic in Nairobi. East Afr Med J. 2008;85:9438-41.

24. Sharma M, Dhungel S, Niroula S, Karki M. Knowledge and acceptance of labour analgesia in pregnant women. J Nepal Health Res Council. 2018;16(3):302-6.

25. Yadav A, Karim HMR, Prakash A, Jena P, Aman K. Correlation of different parity and school education with acceptance of labor analgesia among antenatal women: a questionnaire-based study. Saudi J Anaesth. 2018;12(2):287.

26. Olayemi O, Aimakhu CO, Udoh ES. Attitudes of patients to obstetric analgesia at the University College Hospital, Ibadan, Nigeria. J Obstet Gynaecol. 2003;23(1):38-40.

27. Shidhaye RV, Galande M, Bangal VB, Smita DA, Shidhaye UR. Awareness and attitude of Indian pregnant women towards labour analgesia. Anaesth Pain Intensive Care. 2012;16(2):131-6.

28. Deogaonkar SG, Natekar S. Awareness and acceptance of labour analgesia in rural India. Int J Med Res Rev. 2016;4(12):2170-5.

29. Gari A, Aziz A, Alsaleh N, Hamour Y, Abdelal H, Ahmed RS. Awareness of epidural analgesia among pregnant women in Jeddah, Saudi Arabia. Electron Phys. 2017;9(5):4274-80. 